05

\title{
О вакансионной природе высокотемпературного фона внутреннего трения в твердых телах
}

\author{
(C) С.А. Гриднев, Ю.Е. Калинин \\ Воронежский государственный технический университет, \\ 394026 Воронеж, Россия \\ e-mail: kalinin48@mail.ru
}

Поступило в Редакцию 18 мая 2021 г.

В окончательной редакции 7 октября 2021 г.

Принято к публикации 11 октября 2021 г.

Исследовано высокотемпературное внутреннее трение в аморфном сплаве CuTi. На зависимости внутреннего трения от температуры по обе стороны от температуры стеклования наблюдаются экспоненциальные участки с разной энергией активации. Экспоненциальное увеличение фона внутреннего трения с температурой на обоих участках связывается с миграцией вакансиоподобных дефектов в аморфной структуре под действием механических напряжений, при этом до температуры стеклования мигрируют замороженные дефекты постоянной концентрации. После перехода в состояние термодинамического равновесия концентрация мигрирующих дефектов растет по экспоненциальному закону. По экспериментальным результатам измерения высокотемпературного фона сделаны оценки энергии активации миграции и образования вакансиоподобных дефектов аморфной структуры исследуемого сплава.

Ключевые слова: внутреннее трение, время релаксации, высокотемпературный фон, аморфный сплав.

DOI: 10.21883/JTF.2022.02.52013.146-21

\section{Введение}

Как показали многочисленные экспериментальные результаты по исследованию температурной зависимости внутреннего трения (ВТ), в кристаллах до температур $(0.7-0.8) T_{m}\left(T_{m}-\right.$ температура плавления) происходит почти линейное возрастание ВТ. Выше этих температур часто наблюдается экспоненциальная зависимость $Q^{-1}(T)$, которая и называется высокотемпературным фоном внутреннего трения $[1,2]$. В большинстве случаев высокотемпературный фон ВТ довольно хорошо описывается уравнением вида

$$
Q_{I}^{-1}=A \exp (-H / R T)
$$

где $T$ - температура, $[\mathrm{K}] ; R-$ универсальная газовая постоянная; $A$ и $H-$ константы $[1,3]$.

В настоящее время накоплен большой экспериментальный материал и предложены различные механизмы для объяснения роста ВТ кристаллических твердых тел в этой области температур [1-5]. Теплота активации $H$, вычисленная по выражению (1), во многих случаях оказывалась в несколько раз меньше энергии активации самодиффузии точечных дефектов, что заставляло предлагать сложные механизмы затухания, объясняющие этот процесс.

Высокотемпературный фон ВТ в кристаллах был предметом исследования во многих теоретических работах (например, [6-9]). Теоретическая модель фона ВТ, связанная с миграцией вакансий, была опубликована в работе Эскейга еще в 1962 г. [6], однако экспериментального подтверждения вакансионного механизма фона ВТ в кристаллах долго не удавалось обнаружить по той причине, что этот механизм работает в узкой области при температурах, близких к температуре плавления исследуемого материала, когда измерения трудно осуществить [10]. В работе [8] авторы приходят к заключению, что в образовании фона ВТ участвует не один вакансионный механизм, а целый набор подсистем: вакансий, дислокаций, кристаллитов, атомов примесей внедрения и замещения, при этом фон ВТ можно представить в виде нескольких отрезков прямых на зависимости $\ln Q^{-1}$ от $1 / T$, имеющих существенно разные углы наклона. Однако последовательность смены механизмов, ответственных за увеличение ВТ, ни теоретически, ни экспериментально пока не установлена. Экспериментальные результаты по исследованию высокотемпературного ВТ в различных твердых телах с аморфной структурой показали, что задолго до температуры стеклования экспоненциальный рост ВТ (область так называемой $\alpha$ релаксации) наблюдается в неорганических стеклах с ковалентными связями [11], в металлических стеклах [1214], в объемных металлических стеклах [15-17], халькогенидных стеклах [18,19], полимерах [20-22], который так же, как и в кристаллических твердых телах, можно отнести к высокотемпературному фону ВТ в этом классе материалов, поскольку аморфное состояние этих систем при более высоких температурах переходит либо в кристаллическое состояние, либо в состояние переохлажденной жидкости. Для объяснения экспоненциального роста ВТ в твердых телах с аморфной структурой авторы научных работ предлагают различные механизмы затухания, однако общепризнанной точки зрения на эту проблему пока не существует. Характерной особенностью всех классов твердых тел с аморфной структу- 
рой (аморфные органические полимеры, неорганические стекла, металлические аморфные сплавы, халькогениды и т.д.) является наличие избыточного свободного объема (областей пониженной плотности, характеризуемые определенным распределением по размерам) [23-24], что позволило связать экспоненциальное возрастание внутреннего трения с миграцией вакансиоподобных дефектов аморфной структуры [10,14].

В настоящей работе на примере исследования фона ВТ в металлическом стекле CuTi получены новые экспериментальные результаты, подтверждающие вакансионный механизм высокотемпературного фона ВТ, который связывается с миграцией вакансиоподобных дефектов аморфной структуры (дырок или избыточного объема) в системе с неупорядоченным расположением атомов.

\section{1. Методика эксперимента}

Образцы аморфного сплава $\mathrm{Cu}_{66} \mathrm{Ti}_{34}$ получали закалкой из жидкого состояния методом вращающихся валков [25]. Для этого сплав заданного состава весом в несколько десятков граммов расплавляли в ампуле из кварцевого стекла, расположенной в вакууме, и капля, выдавливаемая газообразным гелием, попадала между двумя вращающимися со скоростью $~ 8000 \mathrm{rpm}$ стальными валками диаметром $50 \mathrm{~mm}$, которые прижимались друг к другу с помощью пружин. За время прохождения между валками капля раскатывалась в виде пленки и затвердевала. Скорость закалки $d T / d t$ составляла $\sim 10^{6} \mathrm{~K} / \mathrm{s}$. При этом образовывались тонкие однородные аморфные пленки толщиной около $30 \mu \mathrm{m}$. Аморфность структуры проверялась рентгеновским методом в отфильтрованном $\mathrm{Co} K_{\alpha}$-излучении на дифрактометре „Дрон-2“. Температура стеклования, определенная методом дифференциального термического анализа, составила $633 \mathrm{~K}$.

Внутреннее трение консольно закрепленных образцов шириной 2-3 mm измерялось в частотном интервале $10^{2}-10^{4} \mathrm{~Hz}$ при относительной деформации не более $10^{-5}$ в области температур $300-900 \mathrm{~K}$ методом свободно-затухающих изгибных колебаний по методике [26]. Погрешность измерения внутреннего трения не превышала 3\%.

\section{2. Результаты эксперимента и их обсуждение}

На рис. 1 представлена температурная зависимость ВТ для аморфного металлического сплава $\mathrm{Cu}_{66} \mathrm{Ti}_{34}$, в которой на высокотемпературный фон ВТ накладывается ассиметричный максимум при $T=690 \mathrm{~K}$, высота которого уменьшается с увеличением частоты механических колебаний по закону $Q^{-1} \sim 1 / f^{1 / 2}$ (вставка на рис. 1 ), где $f$ - частота колебаний образца. Интенсивное возрастание ВТ аморфного сплава начинается при $T \geq 520 \mathrm{~K}$, а в интервале температур 620-650 K на кривых 1

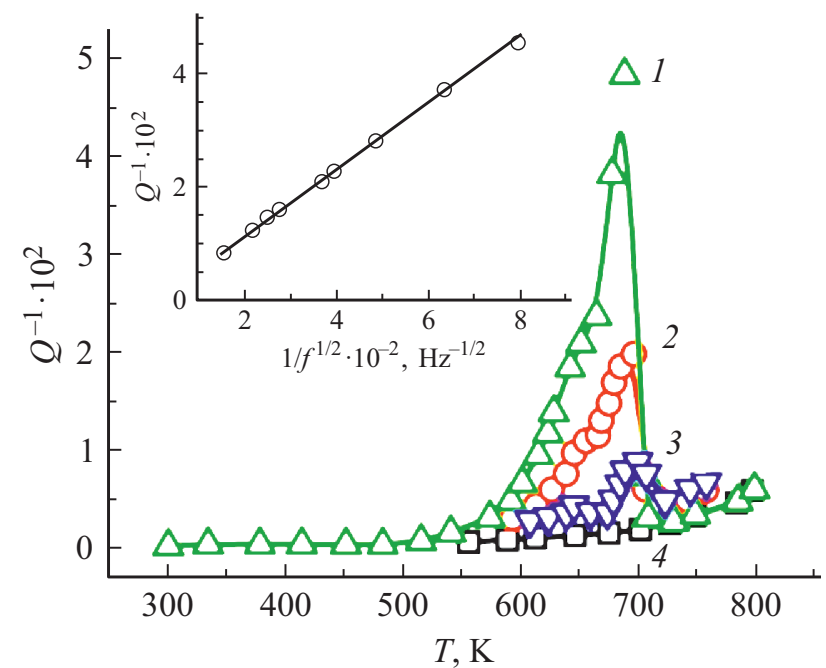

Рис. 1. Температурные зависимости ВТ аморфного (1-3) и кристаллического (4) сплавов $\mathrm{Cu}_{66} \mathrm{Ti}_{34}$ при частоте механических колебаний: 151 (1), 2175 (2), 2786 (3), $200 \mathrm{~Hz}$ (4). На вставке - зависимость высоты максимума ВТ от $1 / f^{-1 / 2}$.

и 2 имеется слабовыраженный перегиб, который при более высоких частотах трансформируется в максимум (кривая 3). Аналогичный максимум наблюдался также и для других аморфных сплавов [27-29]. После нагрева до $780 \mathrm{~K}$, т. е. после перехода аморфной структуры в кристаллическое состояние, на температурной зависимости ВТ нет каких-либо особенностей (кривая 4). Поскольку природа максимума ВТ при температурах 620-650 K не входит в интересы настоящей работы, а заслуживает отдельного обсуждения, остановимся более подробно на анализе фона ВТ в твердых телах с аморфной структурой.

Анализ данных по высокотемпературному ВТ аморфного металлического сплава $\mathrm{Cu}_{66} \mathrm{Ti}_{34}$, представленных на рис. 1, и других аморфных сплавов [29], а также объемных металлических стекол [30] показывает, что величина фона ВТ достигает больших значений при низких частотах и уменьшается с увеличением частоты колебаний образца, причем для частот килогерцового диапазона затухание упругих колебаний в области высокотемпературного фона уменьшается по закону $Q^{-1} \sim 1 / f^{1 / 2}$ (вставка на рис. 1$)$.

Другой характерной особенностью спектров ВТ аморфных металлических сплавов является то, что высокотемпературную часть фона можно представить в виде двух отрезков прямых на зависимости $\ln Q^{-1}$ от $1 / T$, имеющих существенно разные углы наклона (рис. 2). На данной закономерности остановимся более подробно. При изучении внутреннего тела в твердых телах с аморфной структурой анализ ВТ в области высокотемпературного фона (или в области $\alpha$-релаксации неорганических, халькогенидных стекол и аморфных полимеров) ведут с использованием температурно-частотных зависимостей в координатах $\ln \omega=f(1 / T)$, которые являются 


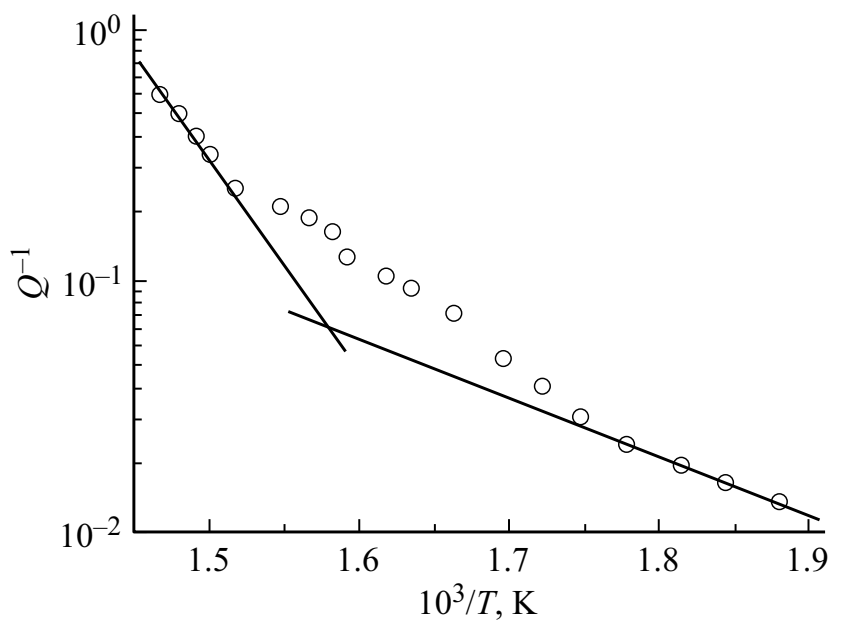

Рис. 2. Температурная зависимость ВТ аморфного сплава $\mathrm{Cu}_{66} \mathrm{Ti}_{34}$ в координатах $\ln Q^{-1}$ от $1 / T$ при частоте механических колебаний $151 \mathrm{~Hz}$. Сплошные кривые - суммы двух экспоненциальных зависимостей с энергиями активации 0.47 и $1.4 \mathrm{eV}$.

криволинейными, что указывает на зависимость этих процессов от температуры $[31,32]$. При таком рассмотрении основное условие максимума $\omega \tau=1$ заменяется на соотношение Деборы [33]:

$$
\omega \tau=c,
$$

где $c$ - безразмерный коэффициент, несет определенную неоднозначность [32]. В некоторых положениях теории релаксационной спектрометрии величина данного коэффициента связывается с масштабностью процесса релаксации: для крупномасштабных процессов этот коэффициент может принимать значение, равное 10, а для мелкомасштабных - единице [20]. При таком подходе двойственная природа стеклования приводит к тому, что энергия активации процесса стеклования состоит из двух составляющих:

$$
U_{\alpha}=U_{1}+U_{2}(T)
$$

где $U_{1}$ и $U_{2}(T)$ - энергии активации первого и второго этапов процесса механической релаксации соответственно. Первая составляющая $\left(U_{1}\right)$ связывается с потенциальным барьером перехода в активированное состояние. Вторая составляющая $\left(U_{2}(T)\right)$ связывается с энергией, необходимой для образования свободного объема и перехода кинетической единицы в соседнее положение [34].

Данный подход, на наш взгляд, является не совсем корректным, поскольку наблюдаемый максимум, как правило, не удовлетворяет условию $\omega \tau=1$, а обусловлен наложением на высокотемпературный фон ВТ потерь, связанных с процессами кристаллизации (в металлических стеклах), или переходом стекла в состояние переохлажденной жидкости (в неорганических, халькогенидных стеклах и полимерах). Это проявляется в наличии ассиметричного пика ВТ как для металлических стекол (рис. 1), так и для других аморфных твердых тел - полимеров [35] и неорганических стекол [36].

$\mathrm{C}$ позиций феноменологической теории неупругости любой релаксационный процесс, проявляемый в виде пика диссипативных потерь на спектре ВТ, может быть описан уравнением стандартного линейного тела в виде [1]:

$$
\operatorname{tg} \varphi=Q^{-1}=\Delta \frac{\omega \tau}{1+\omega^{2} \tau^{2}},
$$

где $\Delta=\left(M_{n}-M_{r}\right) / M_{r}-$ степень релаксации или дефект модуля, $\omega-$ круговая частота, $M_{n}$ и $M_{r}-$ нерелаксированный и релаксированный модули упругости соответственно, $\tau$ - время релаксации, изменяющееся по закону Аррениуса

$$
\tau=\tau_{0} \exp (H / R T)
$$

где $H$ - теплота активации некоторого релаксационного процесса, $\tau_{0}$ - временной параметр, слабо зависящий от температуры, $T$ - температура, $[\mathrm{K}], R-$ универсальная газовая постоянная.

Из соотношения (4) следует, что изменение с температурой времени релаксации $\tau$ приводит к тому, что величина внутреннего трения достигает своего максимального значения при выполнении условия $\omega \tau=1$. Поскольку в исследуемом аморфном сплаве мы не достигаем условия максимума, энергию активации релаксационного процесса можно найти по низкотемпературному склону ВТ в области $\alpha$-релаксации. Так, из формулы (5) и выражения $Q_{\max }^{-1}=\frac{1}{2} \Delta$ можно записать

$$
Q^{-1}=\frac{2 Q_{\max }^{-1} \omega \tau}{1+\omega^{2} \tau^{2}} .
$$

Тогда из формул (5) и (6) для низкотемпературной ветви пика $(\omega \tau \gg 1)$ следует

$$
Q^{-1} \sim \exp \left(-\frac{H}{R T}\right) .
$$

Как видно на рис. 2, на зависимости $\ln Q^{-1}$ от $1 / T$ наблюдаются два прямолинейных участка с энергией активации высокотемпературного фона $U_{b 1}=0.47 \pm 0.02 \mathrm{eV}$ и $U_{b 2}=1.4 \pm 0.2 \mathrm{eV}$ для аморфного сплава $\mathrm{Cu}_{66} \mathrm{Ti}_{34}$. Два прямолинейных участка на зависимости $\ln Q^{-1}$ от $1 / T$ наблюдались и для других аморфных твердых тел: объемных металлических стекол $\mathrm{Zr}_{52.5} \mathrm{Ti}_{5} \mathrm{Cu}_{17.9} \mathrm{Ni}_{14.6} \mathrm{Al}_{10}$ c энергиями активации высокотемпературного фона, равными $U_{b 1}=0.70 \pm 0.02 \mathrm{eV}$ и $U_{b 2}=2.1 \pm 0.2 \mathrm{eV}$ на низкотемпературном и высокотемпературном участках соответственно [30], в халькогенидных полупроводниках системы $\mathrm{Ge}-\mathrm{As}-\mathrm{Se}$ в области $\alpha$-процесса релаксации [18], для стеклопластика в матрице Т-107 [21] и других системах. Во многих полимерах и неорганических стеклах такой анализ не проводился, но наличие асимметрии пика в области $\alpha$-процесса релаксации таких систем не вызывает сомнений [37-40]. Как видно на 
рис. 2, энергия активации релаксационного процесса в области высокотемпературного фона тоже состоит из двух составляющих, однако в отличие от уравнения (3) при данном подходе обе составляющие энергии активации не зависят от температуры.

Тот факт, что в области высокотемпературного фона ВТ пропорционально $f^{-1 / 2}$, может свидетельствовать о диффузионной природе затухания механических колебаний в рассматриваемом диапазоне температур. В физике жидкостей, аморфных полимеров и металлических стекол широкое распространение получили различные варианты теории свободного объема $[41,42]$, в основе которых лежат, по существу, основные положения дырочной теории Френкеля [43]. Свободному объему жидкости Я.И. Френкель придавал смысл избыточного объема в сравнении с объемом кристаллического твердого тела. По его оценке доля свободного объема жидкости составляет около $3 \%$ [43].

Классический свободный объем аморфных веществ (или пустое пространство между атомами) входит в состав атомных структурных комплексов. Его называют структурно обусловленным, геометрическим свободным объемом, распределенным в виде флуктуаций, которые и можно считать вакансиопобными дефектами аморфной структуры [44].

При температуре стеклования в результате флуктуационных перегруппировок атомов возникает локальный флуктуационный объем, превышающий объем делокализации атома, что служит условием перехода кинетической единицы в новое положение с образованием новых структурных объектов. Флуктуационный объем аморфного вещества обусловлен тепловыми смещениями атомов, а его объемная доля слабо зависит от природы аморфных веществ и составляет $f_{g} \approx 0.02-0.03$ [44,45]. Флуктуационное смещение кинетической единицы рассматривается как процесс делокализации атома [46]. В силикатных стеклах он представляет собой смещение мостикового кислорода в мостике $\mathrm{Si}-\mathrm{O}-\mathrm{Si}$, в металлических стеклах — образование вакансиоподобных дефектов, а в полимерных углеводородах — предельное смещение соединительного звена в основной цепи макромолекулы [46].

С повышением температуры подвижность таких единиц возрастает, а наложение механических напряжений приводит к их направленной миграции от областей растяжения в области сжатия. С физической точки зрения это означает, что ВТ пропорционально концентрации замороженных в процессе закалки дефектов $\mathrm{n}$ и средней длине их миграции $L$, т. е.

$$
Q^{-1} \sim n L \sim n \sqrt{D t} \sim \frac{n}{\omega^{1 / 2}} \exp \left(-\frac{E_{m}}{2 k T}\right),
$$

где $D-$ коэффициент диффузии, $t-$ время, $k-$ постоянная Больцмана, $E_{m}$ - энергия активации миграции.

Полагая, что и в случае аморфных металлических сплавов экспоненциальный рост ВТ обусловлен миграцией вакансиоподобных дефектов, можно использовать формулу (8) для оценки энергетических характеристик вакансиоподобных дефектов аморфной структуры. При этом будем считать, что концентрация дефектов аморфной структуры $n$ определяется, согласно [13], как

$$
n=\left\{\begin{array}{ll}
n_{0}, & T<T_{g} \\
A \exp \left(-E_{v} k T\right), & T>T_{g}
\end{array} .\right.
$$

Здесь $n_{0}$ и $A$ - постоянные, $E_{v}$ - энергия образования вакансиоподобного дефекта аморфной структуры при температурах выше температуры стеклования, $T_{g}-$ температура стеклования. Если использовать описанный выше подход к аморфным металлическим сплавам, то энергия миграции вакансиоподобных дефектов должна быть в два раза больше энергии активации высокотемпературного фона на низкотемпературном участке, т.е. $E_{m}=0.94 \pm 0.04 \mathrm{eV}$, a энергия образования, определяемая как разность $E_{v}=U_{b 2}-U_{b 1}=0.93 \pm 0.04 \mathrm{eV}$ для сплава $\mathrm{Cu}_{66} \mathrm{Ti}_{34}$. Еcли использовать данный подход для объемного металлического стекла $\mathrm{Zr}_{52.5} \mathrm{Ti}_{5} \mathrm{Cu}_{17.9} \mathrm{Ni}_{14.6} \mathrm{Al}_{10}$, то получим для энергии активации миграции $E_{m}=1.40 \pm 0.04 \mathrm{eV}$, а для энергии образования $E_{v}=1.40 \pm 0.04 \mathrm{eV}$ [30], т.е. значения энергии образования дефектов оказываются в пределах ошибки совпадающими с энергиями их миграции. Исходя из теории жидкости Френкеля [43] (полагая, что аморфные сплавы - это замороженные жидкости), где в качестве дефектов рассматриваются „дырки“, образуемые путем разрыва одной химической связи между соседними атомами, можно считать, что значения $E_{m}$ и $E_{v}$ должны быть равны.

Таким образом, несмотря на то, что авторы экспериментальных работ в различных аморфных структурах по-разному трактуют причины экспоненциального роста ВТ, высокотемпературную часть ВТ всех твердых тел c аморфной структурой можно представить в виде двух отрезков прямых в координатах $\ln Q^{-1}$ от $1 / T$ с точкой пересечения вблизи температуры стеклования и связать ее с миграцией вакансиоподобных дефектов. При этом если использовать составной образец (например, исследуемый образец сопрягается с материалом, не поглощающим колебания в этой области температур [47]), то по температуре пересечения двух отрезков прямых высокотемпературного фона в координатах $\ln Q^{-1}$ от $1 / T$ можно определить температуру стеклования. Так, в работе [21] измерена температурная зависимость внутреннего трения в стеклоуглепластиках с полимерной матрицей Т-107 в области главного релаксационного процесса, т. е. $\alpha$-релаксации [48]. Стеклоткань, имеющая более высокую температуру стеклования, позволила снизить общий фон ВТ стеклопластика и измерить фон ВТ в полимерной матрице до и после температуры стеклования полимера. Результаты исследований показали, что в области температуры стеклования материала матрицы ВТ не зависит от концентрации наполнителя, а определяется фоном ВТ полимера, по результатам 


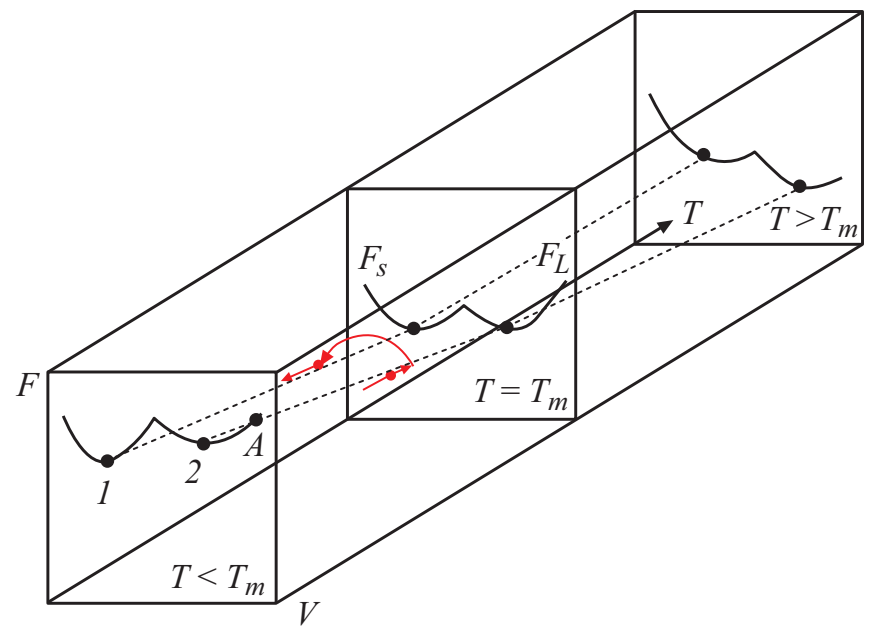

Рис. 3. Изменение свободной энергии конденсированного состояния от температуры и объема.

исследования которого удалось оценить температуру стеклования последнего.

Рассмотренные выше исследования были проведены на относительно массивных образцах, когда вакансиоподобные дефекты за период колебаний не успевают продиффундировать от растянутых участков образца к сжатым. Если же исследовать ВТ в наноструктурированных образцах, то можно реализовать случай, когда в области высокотемпературного фона $Q^{-1} \sim \omega^{-1}$. В частности, исследования высокотемпературного фона ВТ в нанокомпозитах $\left(\mathrm{Co}_{45} \mathrm{Fe}_{45} \mathrm{Zr}_{10}\right)_{x}\left(\mathrm{Al}_{2} \mathrm{O}_{3}\right)_{100-x}$ показали, что в этом случае энергия активации высокотемпературного фона в аморфном металлическом сплаве $\mathrm{Co}_{45} \mathrm{Fe}_{45} \mathrm{Zr}_{10}$ равна энергии активации миграции $H_{b}=E_{m}=1.4 \pm 0.1 \mathrm{eV}[49]$.

Таким образом, высокотемпературный фон ВТ в аморфных твердых телах можно связать и с миграцией вакансиоподобных дефектов аморфной структуры с замороженной (постоянной) концентрацией до температуры стеклования, и с концентрацией, изменяющейся по закону Аррениуса, после температуры стеклования.

Обобщим экспериментальные данные по фону внутреннего трения с применением термодинамической схемы (рис. 3), на которой представлена зависимость свободной энергии $F$ от температуры $T$ и объема $V$, выступающего в качестве структурного параметра конденсированного состояния вещества [50]. Зависимость свободной энергии от структурного параметра $V$ имеет вид потенциальной ямы как для твердого кристаллического состояния $F_{S}$, так и для жидкого состояния $F_{L}$. Такой характер зависимости свободной энергии от структурного параметра обусловлен тем, что в состоянии равновесия система обладает минимумом энергии. Например, упругую часть свободной энергии твердого тела $U$ можно представить, как квадратичную функцию изменения объема $V$ [43]:

$$
U(V)-U\left(V_{\mathrm{o}}\right)=1 / 2 K\left(V-V_{\mathrm{o}}\right)^{2} / V_{\mathrm{o}} .
$$

Здесь $V_{\mathrm{o}}$ - равновесное значение объема, $K-$ модуль всестороннего сжатия.

На представленной схеме изменение свободной энергии конденсированного состояния от температуры и объема представлено в виде двух „желобов“: для кристаллического состояния (с меньшим значением объема) и жидкого состояния (с большим значением объема). Изменение свободной энергии от температуры по дну „желоба“ характеризует состояние термодинамического равновесия (или состояние метастабильного равновесия) системы. Отклонения от состояния термодинамического равновесия (или метастабильного) характеризуют неравновесные (лабильные) состояния.

Для систем, склонным к стеклованию (неорганические стекла, халькогениды и другие системы), быстрой закалкой из жидкого состояния можно добиться того, что при температурах ниже температуры плавления система остается в метастабильном состоянии, характерном для переохлажденной жидкости (точка 2 при $T<T_{m}$ на рис. 3). При температурах ниже температуры стеклования $\left(T_{g}\right)$ структура замораживается, и система характеризуется уже точкой $A$ (рис. 3 при $T<T_{m}$ ). Такое состояние является неравновесным не только относительно стабильного кристаллического, но и метастабильного равновесия, характерного для переохлажденной жидкости. Процесс релаксации аморфной структуры из неравновесного состояния (точка $A$ при $T<T_{m}$ на рис. 3) в состояние метастабильного равновесия (точка 2 при $T<T_{m}$ на рис. 3) и принято называть структурной релаксацией, в отличие от процесса кристаллизации, связанного с переходом в состояние с абсолютным минимумом свободной энергии (точка 1 на рис. 3). В соответствии с изложенным представлением изменение свободной энергии от температуры и объема описывается соотношением

$$
d F=\left(\frac{\partial F}{\partial T}\right)_{V} \cdot d T+\left(\frac{\partial F}{\partial V}\right)_{T} \cdot d V
$$

отсюда

$$
\frac{d F}{d T}=\left(\frac{\partial F}{\partial T}\right)_{V}+\left(\frac{\partial F}{\partial V}\right)_{T} \cdot \frac{d V}{d T} .
$$

Из этого уравнения следует, что в общем случае температурный коэффициент свободной энергии $F$ определяется температурным коэффициентом $(d F / d T)_{V}$ и некоторой величиной, равной температурному коэффициенту изменения объема $d V / d T$, умноженному на коэффициент, зависящий от структуры $(d F / d V)_{T}$. Следовательно, изменение физических свойств аморфных твердых тел, обусловленных изменением структуры в процессе структурной релаксации, можно однозначно связать с наличием в аморфной структуре различного рода дефектов. Отклонение структуры сплава от метастабильного равновесия при охлаждении из жидкого состояния обусловлено замораживанием некоторой 
концентрации дефектных конфигураций. При таком рассмотрении температура стеклования представляет собой температуру, при которой концентрация замороженных дефектов становится равной равновесной, т.е. температура стеклования аналогична температуре замерзания вакансий в кристалле при охлаждении последнего от предплавильных температур.

Нагрев замороженной аморфной структуры металлических стекол до температуры стеклования (рис. 1) приводит к миграции замороженных вакансиоподобных дефектов постоянной концентрации, которая начинает изменяться по закону Аррениуса после температуры стеклования. Наблюдаемая в нашем эксперименте зависимость высокотемпературного фона ВТ для аморфных твердых тел при этом выражается в виде двух отрезков прямых в координатах $\ln Q^{-1}$ от $1 / T$ с точкой пересечения около температуры стеклования (рис. 2) в аморфном состоянии. При этом по низкотемпературному участку высокотемпературного фона ВТ можно оценить энергию активации миграции вакансиоподобных дефектов, а по высокотемпературному - их энергию образования. После кристаллизации аморфной структуры система из локального минимума свободной энергии переходит в кристаллическое состояние, характеризующееся абсолютным минимумом свободной энергии, но при этом его не достигает (стрелка на рис. 3). При охлаждении кристаллической структуры дефекты, характерные для аморфного состояния, отсутствуют, и на зависимости ВТ от температуры каких-либо аномалий не наблюдается (кривая 4 на рис. 1).

В заключение отметим, что в последние годы вновь возникла дискуссия о природе стеклования жидкости: является ли этот переход чисто кинетическим переходом или представляет собой фазовый переход второго рода $[24,51]$. Приведенные выше результаты позволяют ответить на вопрос авторов обзорной работы [51]: „представляет ли собой стеклование чисто кинетическое явление или является следствием перехода к состоянию „идеального“ стекла?“. Экспериментальные результаты свидетельствуют о том, что процесс стеклования представляет собой чисто кинетическое явление, а не является следствием фазового перехода к состоянию „идеального“ стекла. Состояние „идеального“ стекла (по аналогии с кристаллом это стекло без дефектов) должно отражаться на представленной на рис. 3 схеме точкой 2 в локальном минимуме при абсолютном нуле, а состояние идеального кристалла - точкой 1 в абсолютном минимуме при $0 \mathrm{~K}$.

\section{Заключение}

Экспериментальные результаты исследования ВТ в аморфном сплаве $\mathrm{Cu}_{66} \mathrm{Ti}_{34}$ показывают, что в области высокотемпературного фона $Q^{-1} \sim f^{-1 / 2}$, что связывается с миграцией вакансиоподобных дефектов аморфной структуры под действием знакопеременных механиче- ских напряжений. Установлено, что высокотемпературная часть фона состоит из двух отрезков прямых, имеющих существенно разные углы наклона на зависимости $\ln Q^{-1}$ от $1 / T$ с точкой пересечения вблизи температуры стеклования.

При этом низкотемпературный участок фона ВТ связывается с миграцией неравновесных (замороженных) дефектов структуры, когда энергия активации фона ВТ включает в себя лишь энергию активации миграции дефектов. Высокотемпературный участок фона ВТ объясняется миграцией равновесных точечных дефектов реальной структуры, а эффективная энергия активации фона определяется двумя составляющими: энергией активации миграции и энергией образования дефектов. Оценки этих составляющих для сплава $\mathrm{Cu}_{66} \mathrm{Ti}_{34}$ показали, что энергия активации миграции $E_{m}=0.94 \pm 0.04 \mathrm{eV}$, а энергия образования $E_{v}=0.93 \pm 0.04 \mathrm{eV}$.

\section{Финансирование работы}

Работа выполнена при финансовой поддержке Министерства образования и науки в рамках базовой части государственного задания (проект № FZGM-2020-007).

\section{Конфликт интересов}

Авторы заявляют, что у них нет конфликта интересов.

\section{Список литературы}

[1] А. Новик, Б. Берри. Релаксащионные явления в кристаллах, пер. с англ. под ред. Э.М. Надгорного, Я.М. Сойфера (Атомиздат, M., 1975) [A.S. Novick, B.S. Berry. Anelastic Relaxation in Crystalline Solids (Academic Press, NY., London, 1972)]

[2] В.С. Постников. Внутреннее трение в металлах (Металлургия, М., 1974)

[3] Б.Я. Пинес, А.А. Кармазин. ФММ, 22 (4), 632 (1966).

[4] Б.И. Шаповал, В.М. Аржавитин. Механизмы высокотемпературного фона внутреннего трения металлов: Обзор (ЦНИИатоминформ, М., 1988)

[5] G. Schoek, B. Bisogni, J. Shune. Acta Metal., 12 (12), 1466 (1964).

[6] В. Escaig. Acta Metal., 10, 829 (1962).

[7] Б.М. Даринский, Ю.А. Федоров, Т.Д. Шермергор. Физ. хим. обр. мат., 2, 106 (1967).

[8] А.А. Горшков, В.А. Ломовской, Е.К. Наими. Вестник МИТХТ, 4 (6), 86 (2009).

[9] В.Г. Кульков. Релаксационные явления на границах зерен в металлах (филиал МЭИ, Волжский, 2015)

[10] И.В. Золотухин, Ю.Е. Калинин. ФТТ, 37 (2), 536 (1995).

[11] И.В. Андреев, Ю.С. Балашов, О.В. Мазурин. ФХС, 6 (2), 203 (1980).

[12] Н.П. Кобелев, Я.М. Сойфер, И.Г. Бродова, А.Н. Манухин. ФTT, 41 (4), 561 (1999). [N.P. Kobelev, I.G. Brodova, Ya.M. Sořfer, A.N. Manukhin. Phys. Solid State, 41 (4), 501 (1999). DOI: 10.1134/1.1130813] 
[13] И.В. Золотухин, Ю.Е. Калинин. УФН, 160 (3), 75 (1990). [I.V. Zolotukhin, Y.E. Kalinin. Soviet Physics Uspekhi, 33 (9), 720 (1990). DOI: 10.1070/PU1990v033n09ABEH002628]

[14] Ю.Е. Калинин, Б.М. Даринский. Метал. терм. обраб. мет. 35, 15 (2012). [Y.E. Kalinin, B.M. Darinskii. Metal Science and Heat Treatment, 54 (5-6), 221 (2012).

[15] J. Qiao, J.-M. Pelletier, R. Casalini. J. Phys. Chem. B, 117, 13658 (2013).

[16] N.P. Kobelev, J.C. Qiao, A.S. Makarov, A.M. Glezer, V.A. Khonik. J. Alloys Comp., 869, 159275 (2021). DOI: $10.1016 /$ j.jallcom.2021.1592750

[17] В.М. Аржавитин, А.А. Васильев, К.В. Ковтун, М.С. Сунгуров, О.В. Трембач, В.А. Финкель. ФТТ, 57 (7), 1266 (2015). [V.M. Arzhavitin, A.A. Vasil'ev, K.V. Kovtun, M.S. Sungurov, O.V. Trembach, V.A. Finkel'. Phys. Solid State, 57 (7), 1289 (2015). DOI: 10.1134/S1063783415070045]

[18] В.С. Биланич, В.Б. Онищак, И.И. Макауз, В.М. Ризак. ФTT, 52 (9), 1698 (2010). [V.S. Bilanich, V.B. Onishchak, I.I. Makauz, V.M. Rizak. Phys. Solid State, 52 (9), 1820 (2010). DOI: 10.1134/S1063783410090064]

[19] А.Н. Кабанская, В.А. Ломовской, А.А. Горшков, З.И. Фомкина, Е.В. Копылова. Вестник МИТХТ, 8 (5), 89 (2013).

[20] Г.М. Бартенев, А.Г. Бартенева. Релаксационные свойства полимеров (Химия, М., 1992)

[21] Ю.Е. Калинин, А.Т. Косилов, О.В. Овдак, А.М. Кудрин, О.А. Караева, М.А. Каширин, Д.Я. Дегтярев. ЖТФ, 89 (4), 578 (2019). DOI: 10.21883/0000000000 [Y.E. Kalinin, A.T. Kosilov, O.V. Ovdak, A.M. Kudrin, O.A. Karaeva, M.A. Kashirin, D.Y. Degtyarev. Tech. Phys., 64 (4), 535 (2019). DOI: 10.1134/S1063784219040121]

[22] В.А. Ломовской, Н.А. Абатурова, Н.Ю. Ломовская, О.А. Хлебникова, Т.Б. Галушко. Высокомол. соед., серия A, 60 (3), 201 (2018). DOI: 10.7868/S2308112018030045 [V.A. Lomovoskoi, N.A. Abaturova, N.Yu. Lomovskaya, O.A. Khlebnikova, T.B. Galushko. Polymer Science, series A, 60 (3), 284 (2018). DOI: 10.1134/S0965545X18030070]

[23] В.И. Бетехтин, А.М. Глезер, А.Г. Кадомцев, А.И. Кипяткова. ФТT, 40 (1), 85 (1998). [V.I. Betekhtin, A.G. Kadomtsev, A.Yu. Kipyatkova, A.M. Glezer. Phys. Solid State, 40 (1), 74 (1998).]

[24] Д.С. Сандитов, М.И. Ожогин. УФН, 189|,(3), 113 (2019). DOI: 10.3367/UFNr.2018.04.038319 [D.S. Sanditov, M.I. Ojovan. Physics-Uspekhi, 62 (2), 111 (2019). DOI: $10.3367 /$ UFNe.2018.04.038319]

[25] H.S. Chen, C.E. Miller. Rev. Sci. Instr., 41 (8), 1237 (1970).

[26] В.К. Белоногов, И.В. Золотухин, В.М. Иевлев, В.С. Постников. Физ. хим. обраб. матер., 5, 163 (1968).

[27] H.S. Chen, N. Morito. J. Non-Crystal. Sol., 75 (2), 287 (1985).

[28] M. Tan, Y. He. J. Non-Crystal. Sol., 105 (1), 155 (1988).

[29] И.В. Золотухин, Ю.Е. Калинин, А.М. Рощупкин. ФХС, $18(1), 157$ (1992).

[30] Н.П. Кобелев, Е.Л. Колыванов, В.А. Хоник. ФТТ, 45 (12), 2124 (2003). [N.P. Kobelev, E.L. Kolyvanov, V.A. Khonik. Phys. Solid State, 45(12), 2225 (2003). DOI: $10.1134 / 1.1635489]$

[31] Г.М. Бартенев, В.А. Ломовской. Высокомол. соед., серия A, 44 (8), 1331 (2002). [G.M. Bartenev, V.A. Lomovskoi. Polymer Science, series A, 44 (8), 841 (2002).]

[32] В.А. Ломовской. Тонк. хим. техн., 10 (3), 8 (2015).

[33] A.A. Petrukhin, V.A. Lomovskoj. Materialovedenie (Mater. Sci.), 3, 3 (2001).
[34] Г.М. Бартенев, В.А. Ломовской. ЖФХ, 77 (12), 2266 (2003). [G.M. Bartenev, V.A. Lomovskoi. Russ. J. Phys. Chem. A, 77 (12), 2045 (2003).]

[35] Г.М. Бартенев, Д. Шорматов, А.Г. Бартенева. Высоком. соед., серия А., 43 (7), 1152 (2001). [G.M. Bartenev, D. Shermatov, A.G. Barteneva. Polymer Sci., series A, 43 (7), 708 (2001).]

[36] А.А. Валишин, А.А. Горшков, В.А. Ломовской. Инженерный журн. МТT, 2, 169 (2011). [A.A. Valishin, A.A. Gorshkov, V.A. Lomovskoy. Mech. Sol., 46 (2), 299 (2011).]

[37] Т.Р. Асламазова, В.А. Ломовской, А.Ю. Цивадзе. Высокомол. соед., серия А, 55 (12), 1427 (2013). DOI: $10.7868 / \mathrm{S} 0507547513120039$ [T.R. Aslamazova, V.A. Lomovsko, A.Yu. Tsivadze. Polymer Sci., series A, 55 (12), 729 (2013). DOI: 10.1134/S0965545X13120031]

[38] Т.Р. Асламазова, В.А. Котенев, Н.Ю. Ломовская, В.А. Ломовской, А.Ю. Цивадзе. Физикох. повер. защ. матер., $52(6), \quad 621 \quad$ (2016). DOI: $10.7868 / \mathrm{S} 0044185616060073$ [T.R. Aslamazova, V.A. Kotenev, N.Y. Lomovskaya, V.A. Lomovskoi, A.Y. Tsivadze. Protection Met. Phys. Chem. Surf., 52 (6), 1012 (2016). DOI: 10.1134/S2070205116060071]

[39] Т.Р. Асламазова, В.И. Золотаревский, Н.Ю. Ломовская, В.А. Ломовской, В.А. Котенев, А.Ю. Цивадзе. Физикох. поверх. защ. мат., 54|,(1), 92 (2018). DOI: $10.7868 / \mathrm{S} 0044185618010114$ [T.R. Aslamazova, V.I. Zolotarevskii, N.Y. Lomovskaya, V.A. Lomovskoi, V.A. Kotenev., A.Y. Tsivadze. Protection Met. Phys. Chem. Surf., 54 (1), 85 (2018). DOI: 10.1134/S2070205118010021]

[40] В.А. Ломовской, Н.А. Абатурова, Н.Ю. Ломовская, Т.Б. Галушко, В.И. Золотаревский. Высокомол. соед., серия А, 61 (4), 346 (2019). [V.A. Lomovskoi, N.A. Abaturova, N.Yu. Lomovskaya, T.B. Galushko, V.I. Zolotarevskii. Polymer Sci., Series A, 61 (4), 491 (2019). DOI: $10.1134 / \mathrm{S} 0965545 \mathrm{X} 19040114]$

[41] Д.С. Сандитов. ДАН, 464 (6), $705 \quad$ (2015). DOI:10.7868/S0869565215300167 [D.S. Sanditov. Dok1. Phys. Chem., 464|,(2), 255 (2015). DOI: $10.1134 / \mathrm{S} 0012501615100097]$

[42] Д.С. Сандитов. ЖЭТФ, 150 (3(9)), $501 \quad$ (2016). DOI: $10.7868 / \mathrm{S} 004445101609008 \mathrm{X}$ [D.S. Sanditov. J. Experiment. Theor. Phys., 123 (3), 429 (2016). DOI: $10.1134 / \mathrm{S} 1063776116070219]$

[43] Я.И. Френкель. Введение в теорию металлов (Наука, Л., 1972)

[44] Д.С. Сандитов, М.В. Дармаев, В.В. Мантатов. Вест. Бурят. гос. ун-т хим., физ., 1, 15 (2020).

DOI: $10.18101 / 2306-2363-2020-1-15-22$

[45] Д.С. Сандитов, М.В. Дармаев, Б.Д. Сандитов. ЖТФ, 87 (1), 44 (2017). DOI: 10.21883/JTF.2017.01.44017.1807 [D.S. Sanditov, M.V. Darmaev, B.D. Sanditov. Tech. Phys., 62 (1), 53 (2017). DOI: 10.1134/S1063784217010200]

[46] Д.С. Сандитов. ЖЭТФ, $142(1(7)), 123 \quad$ (2012). [D.S. Sanditov. J. Experiment. Theoret. Phys., $115(1)$, 112 (2012). DOI: 10.1134/S1063776112060143]

[47] С.В. Немилов, Ю.С. Балашов. ФХС, 42 (2), 169 (2016). [S.V. Nemilov, Yu.S. Balashov. Glass Phys. Chem., 42 (2), 119 (2016). DOI: 10.1134/S1087659616020139]

[48] Г.М. Бартенев, Д.С. Сандитов. Релаксационные процессы в стеклообразных системах (Наука, Новосибирск, 1986) 
[49] Ю.Е. Калинин, А.В. Ситников, Д.П. Тарасов. Письма ЖТФ, 34 (11), 12 (2008). [Yu.E. Kalinin, A.V. Sitnikov, D.P. Tarasov. Tech. Phys. Lett., $34(6), 459$ (2008). DOI: $10.1134 / \mathrm{S} 1063785008060035]$

[50] И.В. Золотухин, Ю.Е. Калинин, О.В. Стогней. Новые направления физического материаловедения (ВГУ, Воронеж, 2000)

[51] Т.В. Тропин, Ю.В.П. Шмельцер, В.Л. Аксенов. УФН, 186 (1), 47 (2016). DOI: 10.3367/UFNr.0186.201601c.0047 [T.V. Tropin, Ju.W.P. Schmelzer, V.L. Aksenov. 59, 42 (2016). DOI: 10.3367/UFNe.0186.201601c.0047] 